\title{
ABSTRACTS.
}

\section{Aeronautical Units.}

Generally speaking, a correspondent writes, the units used in aeronautical investigations should, if possible, be small enough to give a sufficiently near approximation without employing decimals. For instance, one has a much clearer notion of the order of the difference between, say, 500 and 502 millibars than of that between the corresponding expressions for pounds per square inch, namely, 7.234 and 7.263. To express the pressure in terms of the length of a column of mercury is to introduce unnecessary complications, and the unit of pressure par excellence is the millibar, 69. I I of which corresponds to I lb. per square inch. This fact was discovered long ago by the Meteorological Office. The ordinary pressure at ground level is about rol $4 \mathrm{mb}$, falling to about 260 at a height of ro kilometres. With regard to temperature, the Centigrade degrees are too large, and Fahrenheit are much to be preferred, but the antiquated method of using negative readings, with a zero that is now meaningless, should be dropped, and absolute measure used for all scientific purposes. The figures for temperature on the absolute Fahrenheit scale range from about 5 Io degrees on the ground down to 400 degrees at ro kilometres. As air is so light it is undesirable, in expressing the density, to use too small a unit of volume, and a cubic centimetre in this connection is ridiculous. A convenient system, which gives figures of a suitable order, is to employ grains per cubic foot. The density then runs from about 546 at ground level down to 177 at io kilometres. The above three sets of units seem to be the most suitable for use in practice, giving, as they do, all the accuracy necessary, without requiring decimals, which do not convey such clear ideas, and, moreover, involve a risk of error through the omission or misplacing of the dot. (C. F. Dendy Marshall, "Ministry of Munitions Journal.")

\section{The Seaplane and its Construction.}

The rapid development of the seaplane, as well as the ordinary aeroplane, is due to the war. Germany was not so advanced as either England or France in August, 1914, but since 19I5 the improvement has been so rapid that to-day the German scaplanes are, according to the author, far superior to those of the Entente. The question as to whether the floating aeroplane or the flying boat is the better remains as yet undecided both in Germany and in the enemy countries. The Germans prefer the former, Austria-Hungary and Russia the latter, while England and France use both types in about equal numbers. After pointing out that the type of machine which will give good results upon lakes and still waters is useless for sea work, the author proceeds to describe the various types which have been produced in Germany.

"Two floats are now generally employed and placed each side of the body under the wings, and this necessitates stronger staying than with a central float; each float must be capable of supporting the entire machine, and if they are made long enough a tail float is unnecessary. The Voisin two-decker has, however, three large floats. Diagrams show the arrangements of the floats in various machines, and it is pointed out that a form of float which may be quite satisfactory for support may yet offer too great an air resistance. The author then proceeds to discuss the actual form of the float itself. A number of diagrams are given showing the various types of floats which have been employed, and several types of flying-boats are also criticised." ("Schiffbau," June 12, 1918.) 


\section{Balsa Timber in Costa Rica.}

This timber is of extreme importance in aeroplane construction, as it is the lightest wood so far known. It is exceedingly porous, and is thus suitable for all types of insulation.

The tree will thrive free of parasites on any ground in the Tropics, with the exception of swamp, although it grows best on rich ground In one year they attain a height of Io ft. and a diameter of 4 in., and continue at this rate for two years. In five or six years a diameter of 10 in. is obtained, and such a tree produces at least 200 board $\mathrm{ft}$.

The present supply of this wood is extremely restricted on account of the difficulty of transport in the region where it thrives best. The future of the Balsa trade in Costa Rica appears to depend very largely on whether or not it can be successfully grown by plantings on land prepared for the purpose. ("Aviation," July 15,1918 .)

\section{Advance Rot and Latent Defects in Aeroplane Timber.}

One of the commonest defects of timber is decay (rot, punk, or dote) caused by the action of wood-destroying fungi attacking certain constituents of the wood cell-walls for food, the less resinous woods being more susceptible to attack. When the fungus is in its elementary stages little indication is given of its presence, necessitating a thorough examination of the timber. An account is given in the article of the destructive fungi and their action upon the various woods. The difference between the effects of these and non-destructive fungi is elucidated.

Mention is also made of the decay of wood during shipment through tropical seas. ("Aerial Age Weekly," June 17, 1918.)

\section{The Modern Aeroplane.}

A series of articles, of which the concluding one is published in the issue dated June 27 , has been written by Capt. Barnwell for the "Air Service Journal." These articles treat of the main requirements and essential characteristics which must be borne in mind when designing a modern aeroplane, and they give only a very general outline of the problem, with some special reference to the singleseater scout.

A similar series of articles has been recently published by the same author in the British aeronautical Press. (Capt. F. S. Barnwell, R.F.C., "Air Service Journal," June 27, I918.)

\section{Aeroplanes of To=Day.}

This comprehensive article begins with a short historical sketch showir:s itac gradual development of the aeroplane, and the progress is illustrated by several drawings and photographs. As regards nomenclature, there is a photograph of a machine with the names of the various parts written on it. After a short account of the theory of flight, a description follows, in some cases in considerable detail, of nearly all the present-day machines of all countries, and in each case there are photographic illustrations and undimensioned drawings. The principal dimensions, however, are given for each machine, together with the type and horse-power of the engines, speed of the machine, height to which it will climb, load carried, air endurance, armament, military use for which intended, together with the advantages and disadvantages.

Amongst the machines described, the following are noted :-Bristol monoplane (English); Combat Albatros DI (German); Twin-engine Morane-Saulnier 
(French); Spad Fighter (French); Battleplane D.H.4 (United States); Twin-engine Caproni Battleplane (Italian); Twin-engine Caudron (French); Friedrichshafen and Gotha Bombing Machine (German); Curtiss Flying Boat (American); HandleyPage Bomber (English). (F. L. Faurote, "Society of Automotive Engineers' Journal," July, 1918.)

\section{The Model M.T. 2 Lawson Biplane.}

This is a two-seater biplane designed mainly for sturdiness, manœuvring ability and vision. Care has been taken in streamlining all parts possible. The span of the upper plane is $39 \mathrm{ft}$., the overall length is $25 \mathrm{ft}$., and the weight (loaded) is $\mathrm{I}, 900 \mathrm{lbs}$.

There are two pairs of interplane struts on each side of the body. Ailerons are fitted to the upper wing only.

The cabane is entirely of steel. The legs are welded directly to the connecting tube and further braced by corner plates. Bushings (which are provided to take the main landing wire terminals as well as the wing hinge plugs) are welded in through each end of the connecting tube. The front legs of the cabane also carry the radiator bed plate.

The longerons and vertical struts are of ash in front and spruce in the rear. The longerons are left solid their complete length, while all struts, both vertical and horizontal, have been channelled, but left solid at all points of connection. Steel tubes fitted into sockets are used for horizontal struts as far back as the rear cockpit, and also to carry the load from the tail skid shock absorbers.

In the rear part of the body all fittings are interchangeable.

The engine bed rails rest on top of an ash cross-member and are secured to this by U-bolts. The whole unit is braced by tubes fitted with plug ends which bolt directly to the bed and body fittings in such a manner as to eliminate entirely all wire bracing.

Dual control is used, but either is made dismountable.

The motor section may be flooded around the carburettors and gas tank in case of fire.

The tail group is built mostly of steel.

The machine is fitted with a roo h.-p. Hall-Scott engine driving an $8 \mathrm{ft}$. propeller, but being built for interchangeability can be equipped with a $200 \mathrm{~h}$.-p. motor and adapted for fighting purposes. ("Aviation," June 15, 1918.)

\section{International Aircraft Conference.}

A short account is given of the Conference held in London in the spring of 1918. The benefits accruing from this Conference are emphasised and it is pointed out that such a meeting could not have occurred had it not been for the war, and that it clearly marks the beginning of a new era in engineering work. The subjects considered were: Limits and tolerances for metric sizes of ball and roller bearings, fabrics, dopes, electrical parts, streamline and swaged wires, gasolines and oils, glues and cement, instruments, light alloys, magneto dimensions, nomenclature, rubber, screw threads, spark-plugs, steels, seamless tubing timber, turnbuckles, wheels and tyres, wires and cables. (Coker F. Clarkson,

" Society of Automotive Engineers' Journal," July, 1918.)

\section{International Aircraft Standards.}

The following are some of the specifications adopted at the above Conference (see preceding Abstract) :- 
Steel tubing for structural purposes gives the gauges and dimensions and. tolerances of the standard British steel tubing, which are so arranged that one tube can fit inside the next standard size, leaving a space for brazing or soldering. Glue and cement. The opinion is that the standard methods of making the physical tests of glue are not satisfactory. The method of testing the glue by pulling apart two thin overlapping strips of wood is considered to be probably the best. Other specifications are for dopes, fabric, gasoline-resisting tubing, shock-absorber cord, propeller hub and fixing, wheels and tyres, instruments, magnetos, \&c. (Chas. M. Manly, "Society of Automotive Engineers' Journal," July, I9I8.).

\section{Formation Flying.}

The author of this article treats of the advantages which accrue to aeroplanes which always fly in formation, whether on offensive or defensive patrol. In formation flying, not only are the machines less liable to be shot down by antiaircraft fire, but they also form a much stronger offensive or defensive unit than single machines when atacked by other aeroplanes. As a matter of experience, formations are closely observed by the enemy, and any machine leaving the formation is almost sure to be attacked by superior numbers.

Attention is drawn in the article to the inadvisability of using large numbers of aeroplanes in a single Vee formation, and it is pointed out that two small formations of five or more machines are usually much better for most purposes than one of double that number.

The article is illustrated by several photographs and diagrams. (D. I. Lamb, " Air Service Journal," June 27, 1918.)

\section{Report on Aircraft Supply of Great Britain.}

The Smithsonian Institution have published in their volume of collections an extract from the report for the year 19I7 of the War Cabinet of Great Britain relating to supply of aircraft. They consider this report to be so accurate and so. general in its application that a very wide circulation of this extract is undoubtedly warranted.

The extract deals with the steps taken in matters of administration and control, and is supplemented by some general account of the measures taken as regards supply of aircraft and the development of that supply. It is said that experience shows, as a rule, how from the date of the conception and design of an aero engine to the delivery of the first engine in series by the manufacturer, more than a year elapses; the corresponding period for an acroplane is about half as long. Consequently plans have to be laid for a long period ahead, and the plans are liable to be upset by many uncertain factors. Continuing, it states that risks must be run and new types of design must be adopted at the earliest moment consistent with reasonable assurance that they will constitute a substantial improvement on what is already in use. Orders must be placed, moreover, "for considerable numbers and for delivery over many months, as the large cutput. required for our present flying services can only be obtained by bulk orders permitting a high degree of sub-division. ("Smithsonian Miscellaneous Collections," Volume 69, No. 7, June, I918.)

\section{Temperature, Pressure and Humidity of the Air Over Austria.}

In a somewhat elaborate article, J. V. Berger sets out to investigate the laws of distribution of temperature, pressure and humidity on the earth's surface and in the free atmosphere. The data which are actually discussed are mean values. Those for the surface refer to the several months and are derived from six years; observations at twenty stations; those for the upper air are from eight years" 
observations, all observations in the same height zone being pooled regardless of the time of year. The results are set out graphically in various ways.

In abstracting the following table, heights, temperatures and humidities have been rounded off and temperatures converted to the absolute scale-in the original, heights are given to six significant figures and humidities to four.

\begin{tabular}{|c|c|c|c|c|c|c|c|}
\hline & & 210 & -80 & & & & \\
\hline $\begin{array}{l}\text { Height (metres) } \\
\text { Temperature (abs.) }\end{array}$ & $\begin{array}{l}\cdots \\
\cdots\end{array}$ & $\begin{array}{l}310 \\
280.8\end{array}$ & $\begin{array}{l}780 \\
279 \cdot 5\end{array}$ & $\begin{array}{l}1260 \\
277 \cdot 3\end{array}$ & $\begin{array}{l}1780 \\
274.7\end{array}$ & $\begin{array}{l}2310 \\
272.6\end{array}$ & \\
\hline Humidity $\% \quad \ldots$ & $\ldots$ & $7^{6}$ & 70 & 63 & 59 & $5^{6}$ & \\
\hline $\begin{array}{l}\text { Height (metres) } \\
\text { Temperature (abs.) } \\
\text { Humidity \% }\end{array}$ & $\begin{array}{l}\cdots \\
\cdots \\
\cdots\end{array}$ & $\begin{array}{l}2780 \\
271.8 \\
54\end{array}$ & $\begin{array}{l}3300 \\
266.9 \\
53\end{array}$ & $\begin{array}{c}3790 \\
264 \cdot 5 \\
5^{1}\end{array}$ & $\begin{array}{l}4260 \\
263 \cdot 0 \\
43\end{array}$ & $\begin{array}{l}4830 \\
25^{8} .0 \\
5^{2}\end{array}$ & \\
\hline $\begin{array}{l}\text { Height (metres) } \\
\text { Temperature (abs.) } \\
\text { Humidity \% } \quad \ldots\end{array}$ & $\begin{array}{l}\cdots \\
\cdots \\
\cdots\end{array}$ & $\begin{array}{l}5240 \\
254.8 \\
52\end{array}$ & $\begin{array}{l}5850 \\
250.1 \\
56\end{array}$ & $\begin{array}{l}6260 \\
246.2 \\
60\end{array}$ & $\begin{array}{l}6860 \\
242 \cdot 5 \\
58\end{array}$ & & \\
\hline $\begin{array}{l}\text { Height (metres) } \\
\text { Temperature (abs.) } \\
\text { Humidity \% } \quad \ldots\end{array}$ & $\begin{array}{l}\cdots \\
\cdots \\
\cdots\end{array}$ & $\begin{array}{l}7270 \\
239 \cdot 5 \\
54\end{array}$ & $\begin{array}{l}7870 \\
234.8 \\
57\end{array}$ & $\begin{array}{l}8240 \\
23 \mathrm{I} .0 \\
53\end{array}$ & $\begin{array}{l}8880 \\
227 \cdot 2 \\
5^{6}\end{array}$ & $\begin{array}{l}9260 \\
223 \cdot 0 \\
54\end{array}$ & $\begin{array}{c}9870^{\circ} \\
221.6 \\
5^{6}\end{array}$ \\
\hline
\end{tabular}

Abstractor's Note.-The temperatures shown in this table show curious: irregularities: they are in general agreement with those computed by Gold (Meterological Office Geophysical Memoirs No. 5, p. 82) for Vienna. The new temperatures for the third and fourth kilometres are the higher by about $2 \mathrm{a}$. On the other hand at the ninth kilometre there is an equal difference with the opposite sign. The author is evidently unaware of the suspicion which attaches to all hygrometric measurements at very low temperatures.

$$
\text { (J. V. Berger, “ Osterreichische Flug-Zeitscrift," May, I9I8.) }
$$

\section{Air Propeller Performance and Design by the Specific Speed Method.}

A new method is developed for the design of geometrically similar propellers. It is the "Specific-Speed " method already in use in connection with centrifugal" fans and pumps, \&c., and it depends on the fact that the power is proportional to the cube of the speed and to the fifth power of the diameter, other things being: constant.

$$
\begin{aligned}
& \text { Hence :- } \\
& \qquad \begin{array}{l}
\mathrm{V}=\mathrm{CND}, \\
\mathrm{P}=\mathrm{C}_{2} \mathrm{~N}^{3} \mathrm{D}^{5}, \cdot \cdot(a) .
\end{array} \\
& \text { in which } \\
& \mathrm{V}=\text { Velocity of forward movement of propeller relative to still air. } \\
& \mathrm{P}=\text { Power reduced to standard air density. } \\
& \mathrm{N}=\text { Rotational speed. } \\
& \mathrm{D}=\text { Diameter. }
\end{aligned}
$$

whence

$$
\mathrm{N}=\mathrm{C}_{3} \frac{\mathrm{V}}{\mathrm{P}_{\frac{1}{2}}} \cdot \cdot \cdot(c)
$$

If $\mathrm{V}$ and $\mathrm{P}$ are unity, then $\mathrm{C}_{3}$ is the speed required to produce unit velocity with unit power, and is called the "specific speed." Similarly the "specific 
diameter" and the "specific tip speed" can be obtained. The units chosen are Ioo miles per hour and $100 \mathrm{~h} .-\mathrm{p}$.; in other words, the specific propeller can be regarded as one that will produce a velocity of 100 miles per hour with a power of roo h.-p.

There is a table giving data from experiments on models, and therefrom the specific-speed, specific-diameter and specific-tip speed are deduced. Curves are drawn from this data, which can be used for actual calculations, and in an appendix several numerical examples are given to illustrate the use of these curves. The following is one of these examples :-

Given : Velocity $=80$ miles an hour.

Useful power $=\mathbf{1} 20$ horse-power.

Air density $=0.070$ pound per cubic foot.

Speed $=1,300$ revolutions per minute.

Determine : Diameter of propeller required.

Efficiency.

Effective horse-power.

Torque and thrust.

(a) Power at standard air density $=\mathrm{I} 20 \mathrm{X} \frac{0.075}{0.070}=128.5$.

$$
\begin{gathered}
\text { Then : } \mathrm{P}=\frac{\mathrm{I} 28.5}{100}=\mathrm{I.285} . \\
\mathrm{V}=\frac{80}{100}=0.80 \\
\mathrm{~N}=\mathrm{I}, 300
\end{gathered}
$$

(b) From formula (1a) $\mathrm{N}_{\mathrm{s}}=\mathrm{N} \frac{\mathrm{P} \frac{1}{2}}{\mathrm{~V} \frac{5}{2}}=2,580$.

(c) From curve III, for $\mathrm{N}_{\mathrm{s}}=2,5^{80}$.

we have $D_{s}^{\prime}=5.37$ and efficiency $=0.735$.

(d) From formula (2), $\mathrm{D}=\mathrm{D}_{\mathrm{s}} \frac{\mathrm{P} \frac{1}{2}}{\mathrm{~V}_{\frac{8}{2}}}=9.65$ feet.

(e) Effective power $=120 \div 0.735=\mathrm{I} 63.5$ horse-power.

(f) Torque and thrust are found by the usual formulæ.

(M. C. Stuart, "American Society of Naval Engineers' Journal," May, i918.)

\section{White Pine in Aeroplane Work.}

A policy now effective in American aeroplane production is that of supplementing spruce wood supply by using selected timber of other more widely distributed commercial varieties. It is said that exhaustive tests made by the Forest service, followed by experiments in construction, have proved that the requisite qualifications for aeroplane building are possessed in varying degree by other woods besides spruce, notably white pine, and that use of them was immediately decided upon by the Aircraft Board.

It is not intended to displace the spruce with the other woods in such vital parts as wing spars, interplane struts, \&c. ("Air Service Journal," July 25, 1918.) 


\section{Manufacturing the Curtiss Aeroplane Cylinder.}

The cylinder blanks are forged from pieces cut from long bars of steel, and they go through two forging operations. The first machining operation is to rough-turn the outside, then a $2 \frac{1}{2}$ inch hole is drilled, enlarged by a second drill to$3 \frac{1}{2}$ inches, and by a third drill to $4^{\frac{3}{1}}$ inches diameter. Originally there were great difficulties with the drills, owing to the heavy duty, which was got over by inserting a safety device of a shearing pin. The valve seats are then machined, and a steel plate is welded on to the top of the cylinder, to which the outside of the jacket is finally brazed. The original forging weighs roo pounds and the finished cylinder 9 pounds. There are many photographs showing the various operations described. (G. D. Ranger, "American Machinist," August, I918.)

\section{Mineral Oils for Lubricating Aero Engines.}

Castor oil has so far been the best lubricant for aero-engines, owing to its. high viscosity even at high temperatures, its high flash-point and low freezing-point. A further point is the increased efficiency of the engine owing to the decomposition: of castor oil tending to form glycerine and fatty acids, which, attacking the metal, form metallic soaps and make a tight joint between piston and cylinder. This, however, gives rise to wear in time. The author has experimented with stable mineral oils possessing the advantages, but not the disadvantages, of castor oil. It is hoped to get oils a little less dense than castor oil, with a comparable fluidity and flash-point. The freezing-point of such oils would be appreciably higher. (Boyer, “ Revue des Produits Chimiques,' May I5, 19r8; " Genie Civil," August I7, 1918.$)$

\section{The Clement Bayard Rigid Airship.}

The article contains the specification of the letters patent (No. 1, 265,302) issued by the U.S.A. Patent Office on May 7, 1918, to A. Clement Bayard, covering a new system of construction for rigid airships.

The invention has for its object a rigid airship whose girder can withstand the strains due to its own weight when resting upon two supports conveniently situated at two points in its length. It aiso relates to special devices for deflation of the gas ballonets, for rapidly removing the outer envelope, for laterally guying: the girder throughout its length, and also for preserving one or two inflated ballonets for maintaining the girder in its normal vertical position. It is claimed that thus, when the airship is resting on the ground, it would be protected from. the effect of wind capable of turning it from its moorings.

The girder is constituted of the lower framework by the communication passage extending throughout the entire length, the upper framework of light beams, the uprights by vertical pylons located in the median plane, the diagonals. by wires or cables, and the transverse rings situated in the plane of the uprights. by framework members connected by a bracing of a triangular system of wires under tension, thus assuring the non-deformation of the external contour. An essential feature of the invention is the fixing of the two points of support (for which purpose the cars are utilised) so as to localise the compression strains in the lower framework, and so that the upper framework is exposed to tension strains only. With regard to the shock absorbers, a detailed description is given of devices to be used so as to cause the girder to bear directly on the appropriate points of support.

Several diagrams are reproduced showing the above, together with the tearing mechanism, and drums for winding and unwinding the blinds, \&c. ("Aviation,", July $1,1918$. 


\section{Roland Biplane D.II.}

This machine is a single-seater scout which made its first appearance about March, I9I7, and is still often met with by Allied pilots. It is a small machine with an upper wing span of about $291 \mathrm{ft}$, and with a body of length $22.8 \mathrm{ft}$. The total weight fully loaded is 1,820 lbs., and the loading per sq. ft. $7 \cdot 36 \mathrm{lbs}$.

The fuselage is of monocoque type of oval section terminating in a vertical knife edge at the tail. The construction is extremely light, its strength depending only on the ply-wood shell, and the very thin longerons. An extension of the fuselage structure tapering upwards carries the upper wings and the radiator. Two shoulders at the base serve for the attachment of the lower wings.

The structure of the wings does not present any unusual features. Ailerons are fitted to the upper wings only, and are unbalanced. A petrol tank is carried inside the left-hand upper wing.

The rudder and elevators are balanced, and have frames of steel-tube; but the fixed fin and tail plane are of wood.

The motor is a 160 h. -p. 6-cylinder Mercedes.

At the time of its first appearance this machine showed many original features, and has to be reckoned among the best of enemy scout machines. ("L'Aerophile," May, I9I8.)

\section{Austrian "Berg" Single=Seater Fighter.}

The Austrian Berg Single-Seater Fighter appears to have been designed aerodynamically and structurally with a view to rapid production, and the object has been attained by simplicity of detail rather than by any skimping of good workmanship. The latter is good, though the finish is not so thorough as on some machines, and the materials used are better than in many German aeroplanes.

The position of the top plane relative to the pilot is such that it obstructs the view to a small extent only. There is really no blind spot beyond a few yards in front of the machine, the chord of the plane (when projected) passes through the pilot's line of vision rendering the view forward and upward very good. The body is deep, and the pilot's seat fairly high in it, extra depth having been obtained by deepening the turtle back, which has roughly the shape of a man's head and shoulders, thus providing a stream-line screen for the pilot's head without obstructing the view. This screening and the minor fact that arm-rests are provided for the pilot renders the cockpit rather comfortable for long flights. Except in front the turtle back does not cover the whole width of the top of the body, but comes to a point in front of the fin. It has small windows in front of the pilot; apparently to admit light on to the instruments.

The flat-sided body is constructed similarly to the older Albatross type, i.e., of longerons and struts of small sections covered with three-ply wood. It differs, however, in that it has only four longerons, the auxiliary rails having been deemed unnecessary.

The controls are of the usual type; the control lever, which is free to oscillate backwards and forwards for operating the elevator, is forked around a rocking shaft mounted rather higher above the floor than usual. A short cable from the lower end of the "joystick" limits the movement of the lever, thus preventing damage to the elevator when the machine is on the ground.

The ailerons are operated by cables attached to them by means of cranks resting in slots in the planes. There is a somewhat unusual arrangement whereby the positive cable is taken to the front arm of the crank, so that it is the return cable that pulls the wing flap down. To bring about this action, the crank on the rocking shaft points downwards not upwards. 
The foot-bar operating the rudder is of the $T$ type, i.e., the cables are attached to a crank projecting forward at right angles to the bar. The foot-guards consist of two layers of spiral springs.

The engine, probably a $200 \mathrm{~h}-\mathrm{p}$. Austro-Daimler, appears to have been completely covered in. It is mounted on two spruce bearers made up of three laminations mounted on four transverse partitions. The armament apparently consists of two machine-guns with interrupter gears.

The under-carriage is judged to have been of the Vee type.

The wings are of equal span, the upper plane having a distinct reverse curvature beginning behind the rear spar, and presenting a considerable area of concave surface.

The tail planes are made of steel tubing throughout, and the section is cambered by bending the single tubes forming the ribs. The incidence of the tail plane is adjustable but not during flight. ("Aerial Age," June 24, 1918.)

\section{The Importance of Numbers in Aerial Warfare.}

Mr. F. W. Lanchester, in his book "Aircraft in Warfare," lays great stress on numerioal superiority as being of fundamental importance in maintaining aerial supremacy. While "quality" superiority is certainly desirable, it involves time, and as time is precious, it is suggested that quality can be overcome by quantity, and a mathematical examination into the advantages of "quantity" superiority is given. Allowances are made for quality to enter into the calculations by the introduction of ability factors.

Assume two groups of fighting aeroplanes containing $a$ and $b$ machines, and let the quality of the two groups be $A$ and $B$ respectively. Then if $x$ and $y$ be the numbers in groups $I$ and 2 respectively at any time $t$, and if the rate of decrease in the numbers of group $I$ is proportional to the surviving numbers of group 2 , and vice versa.

$$
\frac{d x}{d t}=-B y \text { and } \frac{d y}{d t}=-A x
$$

whence $x=a \cosh t \sqrt{ } A B-b / \frac{\bar{B}}{\sqrt{A}} \sinh t \sqrt{ } A B$

and $y=b \cosh t \sqrt{ } A B-a / \overline{\sqrt{B}} \sinh t \sqrt{ } A B$

Assuming $\mathrm{AB}$ to be constant in order to obtain results comparable on the time scale, it is shown that when $a=2,000$ and $b=1,000$, group 2 will have been completely annihilated and group 1 will have lost 29.4 per cent., 2 I per cent., I 3.4 per cent., 8.7 per cent., and 6.5 per cent. of its machines if the ability ratios be $1: 2,2: 3,1: 1,3: 2$ and $2: 1$ respectively, the ratios of the time taken being $88 \mathrm{I}, 7^{1} 3,55^{\circ}, 433,370$. This proves that numerical superiority is the controlling factor even with the quality factor against it. Curves are given showing how the numbers fall off in the two groups after fighting begins.

It is also possible to calculate, from the equations, the advantage to be derived in separating the enemy group by superior strategy.

The equations can also be used to prove Lanchester's $n^{2}$ law. It is shown that the ability ratio $B / A$ must be equal to $(a / b)^{2}$ in order that the two groups should lose all their machines simultaneously. 
It is further proved that if the odds be $n$ to I against the smaller group, i.e., if $a=\mathrm{nb}$, the smaller group will by the time of its annihilation have inflicted an equal loss on the larger group if its quality be $2 \mathrm{n}-\mathrm{I}$ times that of the larger, i.e., if $\mathrm{B} / \mathrm{A}=2 \mathrm{n}-\mathrm{I}$. (Dr. J. G. Goffin and H. T. Booth, "Aviation," June I 5 , 1918.)

[Note.-The writer submits that with aeroplanes of similar types, but of the classes of efficiency, in combat; the one class greatly inferior to the other, that "The rate of decrease in the numbers is proportional to the surviving numbers. of each group," and that hence, if there are twice as many machines of the inferior class, this group of aeroplanes "will annihilate its opponents, with a loss of less. than a third of its effectives." The argument is considered to be fallacious, and not borne out at the front. Since aeroplanes with a greatly superior performance can perform duties unmolested, engage, and break off, combat at will, and thus inflict damage on their opponents out of, all proportion to their numbers. The effect of the performance of the aeroplane on the moral of pilot, observer and squadron is not realised by the writer, but it is all-important in the field.]

\section{Aeroplane Pigeon Tests.}

Tests concerning the extent to which carrier pigeons can be used in connection with aircraft in flight have been conducted at Fort Sam Houston, Texas, by the Department Signal Office, and are said to have been entirely successful.

In releasing the pigeons from the aeroplane the birds are thrown by the pilot so as to clear the machine and the immediate current of air going with it. The birds then drop until they reach the proper height for easy natural fight, when they circle about just as they do after rising when released on the ground, and then start back to the loft. Pigeons used by the Government carry either a band marked U.S.A. and a serial number, or have "U.S. Army" stamped on the under side of the wing feathers. ("Air Service Journal," July 25, 1918.)

\section{Present=Day Problems in Aeronautics.}

The purpose of the article is to discuss $(a)$ present-day problems which have a bearing in creating the new type of aircraft that must come, and $(b)$ the methods of operation and commercialism that will be necessary.

America's problem is to turn out machines in sufficient quantities to help: materially the Allied cause. In analysing the problem it is to be remembered that the performance of the aeroplane itself is not the vital factor, but that production capabilities and strategical performance may outweigh technical possibilities. As an example of turning engineering disadvantage into strategic advantage the German Albatross is cited-a machine that was built to suit the Ioo h.p. Mercedes engine which was practically standardised for German aircraft when the war broke out.

America has to contend against lack of manufacturing experience and production methods for foreign design, lack of equipment for testing and research, transport difficulties and want of first-hand knowledge of strategic requirements. Against these may be set the advantages accruing from knowledge of quantity production and of the value of standardisation, mass of available data and natural creativeness.

Aircraft design may be divided into several branches, aero-dynamics, structure, mechanical arrangement, production and accessory design.

Aero-dynamics in its fundamentals is simple, there is no final necessity for complicated analysis.

Aeroplanes must be designed for specific uses, a deeply cambered wing gives great lift at high angles and is ideal for weight carrying, but it cannot be driven 
to speed with extra power. For speed, a wing better streamlined used at small angies must be used, this can be driven to greater lift by increasing speed or by adding greater wing area. Increasing speed increases landing speed, and consequently new landing systems must be developed (including brakes and landing gear) in order that the pilot may be able to land within the least possible area and on rough ground. The question is discussed at length and illustrated with diagrams, different types of wings and the positions of the centre of gravity are considered.

Adding wing area involves increased weight, and to every $\mathrm{I}$ lb. engine weight a designer must add 3 lbs. to his total. Moreover, there is an increase of "parasitic" surfaces (struts, radiator, landing gear, etc.), which make up about 6o per cent. of the resistance of a modern machine.

Then there are three general mechanical arrangements to consider-monoplanes, biplanes and triplanes. The relative merits of the three types are considered having regard to the aero-dynamics of the machine (for which the monoplane is the best type of design), its structural design and the extent of the "blind spot," which is probably least in a triplane.

Finally, the engine question is discussed and the value of research is indicated, particularly with regard to high altitude flying, for which new means of propelling and even special fuels may be needed. ("Aviation," July I, I9I8; "Aerial Age Weekly," July I, 1918.)

\section{Fluid Disturbance Caused by Aerofoil Motion.}

The investigation is an attempt at calculating the extent of the region of a fluid disturbed by a " supporting surface," such as an aerofoil moving through it. The problem considered is two-dimensional, and is based on tables of resistance coefficients of a flat plate at different angles of incidence, as given by Bolzmann in "Zeit. für Flugtechnick u. Motorluftschiffahrt," IgI I. Values of K, Kx, Ky, $\mathrm{Kd}$, and $\mathrm{Ks}$ are given, $\mathrm{K}$ being the coefficient of the resultant force on the plate, $\mathrm{Kx}$ the drag coefficient, $\mathrm{Ky}$ the lift coefficient, and $\mathrm{Kd}$ and $\mathrm{Ks}$ the coefficients of the forces on the pressure and suction sides respectively.

It is assumed that the depth of the disturbed region is given by $\mathrm{R}=\mathrm{KF} \sin a$ where $a$ is the angle of incidence, $\mathrm{K}=\mathrm{K} / \sin ^{2} a=\mathrm{Kx} / \sin 3 a=\mathrm{Ky} / \sin ^{2} a \cos a$ and $\mathrm{F}$ the area of the plate, or since the problem is two-dimensional $\mathrm{F}$ is proportional to breaclth of the plate. $R$ is also split up into component parts $R d$ and $R s$, due to the pressure and suction side respectively. A table is appended giving the values of $R, R d$, and $R s$ per unit value of $F$, and the results are plotted against angle of incidence varying from $0^{\circ}$ to $90^{\circ}$. R varies between 2.2 units of length at $0^{\circ}$ to 0.55 at $90^{\circ}$; the former value, which is indeterminate, is obtained by a continuation of the curve.

A similar calculation is carried out for a surface whose cross section is a circular arc; in this case, however, $\mathrm{R}$ and $\mathrm{K}$ are not split up into the component parts due to the pressure and suction sides; $R$ varies between about 3 units at $0^{\circ}$ to 0.59 at $90^{\circ}$. A mean value of the inclination of the streamlines within the disturbed region to those without is also given. (H. Randisch, "Osterreichische Flug-Zeitschrift,' Nos. 7 and 8, 1918.)

\section{The Lateral Dihedral.}

Stabilising by means of the lateral dihedral is not due to change in the projected plan area of the wings when the aeroplane banks, but rather to the sideslipping in the direction of the inner wing causing a lift on the latter, and at the same time a force in the opposite direction on the outer wing.

A drawback in the monoplane was the tendency to have the wings projecting 
upwards and outwards from the centre of gravity. The principle of the dihedral correctly applied demands that the centre of gravity should be above the centre of support of the wings, pendulum action and rolling being thus eliminated. Moreover, the centrifugal force in turning is useful in balancing the banking.

With regard to biplanes with a dihedral, the only ones that deserve to survive are those in which the lower wing only has a dihedral, they have a high factor of safety, and the centre of gravity is higher in relation to the dihedral.

Weight distribution also plays an important part, for if the masses of the machine are so distributed that the aeroplane has a virtual axis of inertia downward and forward, the upward lateral dihedral causes instability and a neyative or downward dihedral causes stability. Experience on a marine aeroplane that has its inert masses on a line running downwards from the centre of gravity confirms this, for if the near wing encounters a gust, rotation occurs about this axis, and the wing comes more into prominence instead of going out of the grust. (W. R. D. Shaw, "Aerial Age Weekly," July I, I9 8.)

\section{Water $=$ Gas for Balloons.}

War requirements have given occasion for a greatly increased consumption of gas for ballooning. But water-gas as manufactured for domestic purposes is a very poor lifter. Therefore to produce gras suitable for that use, the methods of manufacture must be changed. In order to reduce the specific gravity of the gas, it becomes necessary either to eliminate or to reduce to a minimum all those components which have the highest specific gravity. These are carbon dioxide, illuminants, methane, carbon monoxide, and nitrogen. It is also necessary to increase the proportion of the gas having the lowest specific gravity, which is the hydrogen. Since the carbon dioxide and carbon monoxide are derived from the action of the steam upon the heated carbon, this at once suggests the elimination of steam during the gas-making process. It is a well-known fact that the action of heat upon certain crude oils and distillates causes them to "crack" up to form a series of hydrocarbon vapours. The composition of the hydrocarbons varies considerably; however, all of them are made up of carbon and hydrogen. The temperature at which this reaction takes place ranges from about $1,200^{\circ} \mathrm{Fahr}$. to about $1,500^{\circ}$. A higher temperature causes the hydrocarbons to dissociate and to form free carbon and hydrogen. Consequently this condition sugrgests an increase in temperature in the gas machine, with the result that the proportion of free hydrogen will be increased.

It is not easy, however, to apply these theories to practical operations, on account of certain limiting factors. The temperature range within the gas machine is limited to about $1,65^{\circ}$ to $1,700^{\circ}$ Fahr. for its lowest value, because below this temperature all hydrocarbon vapours will not dissociate, with the result that the finished gas will contain too high a percentage of illuminants and methane, which will affect the lifting power very materially. From a hydrogen producing standpoint, the higher the temperature, the more favourable will be the conditions; however, the maximum temperature is limited by the fusion point of the checker brick. Consequently, in order to obtain the best results, the crude oil is introduced in the generator, because at this point a temperature of about $2,000^{\circ}$ Fahr., or even greater, can be maintained without injury to the apparatus.

The method of operation is as follows:--The gas machine is heated slowly until a temperature of about 1,700 to $1,75^{\circ} \mathrm{Fahr}$. is reached in the carburettor and superheater. It generally requires from six to eight hours until the temperature conditions become uniform and constant. It is very important not to attempt to force the temperature too rapidly, because this frequently results in the burning out of the generator grate bars, and it may cause serious damage to the lining in the generator and the checker brick in the carburettor. It has been found very desirable to admit a certain amount of steam underneath the grate bars of the 
generator during the blow, which has a tendency to chill the bottom of the fuel bed, by which an overheating of the grate bars is avoided. As the steam is forced through the fuel bed during the blow, it results in the production of an additional amount of combustion gases, which are burned in the carburettor and superheater by introducing the proper amount of air in these two shells. Therefore, the effect of the steam which is injected underneath the grate bars during the blow is not only to keep the same cool, but in addition to this it has a tendency to produce more heat in the carburettor and superheater, and consequently a uniform temperature and constant conditions are more readily attained. Gas of any specified lifting power, not exceeding $47 \mathrm{lbs}$. per $\mathrm{I}$, ooo cubic feet, may be produced by regulating the temperature. ("American Gas Engineering Journal," August 3, 1918.)

\section{An Austrian Memorandum on a Meteorological Service for the Air Service in Peace Time.}

The usefulness of a daily observation and forecast of the weather for flying was recognised in Germany before the war, where there existed a "Flyers" Warning Service." Such a service only came into being in Austria since the war, and at its best was merely the usual forecast on account of the poverty of the telegraphic connections. The arrangements for a weather service in the field have proved good and ought to be made permanent. A regular Vienna-Kiev service has been begun for military purposes. The task of such a service is twofold, first, to give information of the existing weather conditions, second, to forecast changes. The existing meteorological observations supply the first, but there must be communication two or three times daily as at present, and not only once, as before the war. In the air accurate observation of the speed of the wind and the distribution of clouds is required. The speed of the wind increases with altitude to a considerable extent in our latitude, $e . g$., over Vienna the speed of the wind on a yearly average is 8 metres per second, $r, 000$ metres up, and ro metres per second, 2,00o metres high. On the average it amounts to 30 to 40 $\mathrm{k}$.metres per hour, at altitudes from $\mathrm{I}$ to $2 \mathrm{k} . \mathrm{m}$. above ground level. Taking the speed of the machine itself at about $120 \mathrm{k} . \mathrm{m}$. per hour, the effect of such a retardation due to the wind is not to be neglected.

To determine the strength of the wind small balloons, filled with hydrogen, so-called pilot balloons, are sent up and closely followed by a theodolite from the earth. From the changes in position at successive intervals the direction and strength of the wind is determined. Observation of the distribution of pressure and temperature among the clouds is obtained by the use of larger balloons and kites which are attached to wires and carry registering instruments.

Experience has shown that for prediction with regard to visibility and mist the measurements at high altitudes are much more important than those near the earth, as changres first become evident higher up. Although there are already a considerable number of pilot balloon stations registering three times daily, only a few kite stations exist. In Germany there are many more kite stations, so that their information regarding the state of the atmosphere is much more accurate.

The following is a sketch, based on the experience gained during the war, of what is required of a meteorological service:-

A central State organisation must be instituted which, on procuring its data, sends it by telephone or telegraph to all fying centres. The Austrian and Hungarian organisations must be separate, however, the one connected with the Central Institute of Meteorology and Geodynamics in Vienna and the other with the State Institute of Meteorology and Earth Magnetism in Budapest. The already existing weather departments in each of these must be extended. Each institute must have two kite stations and ro-15 pilot stations. Kite stations 
should be in uninhabited parts because of the wires, while each flying ground should have a pilot balloon station.

Expenses will be large-Kr. $\frac{1}{2}$ million for the two central institutions, while collaboration with neighbouring States, especially German, is necessary to effect a proper distribution of the ranges covered by the stations. The Naval Hydrographic Office in Pola, the Naval Observatory in Trieste, the Meteorological Institute in Agram, and in Sarajeva, should be connected with the two central organisations, which ought also to work in conjunction with institutions for technical education. ("Osterreichische Flug-Zeitschrift," June, I918. By Prof. F. M. Ritter v. Exner, Director of the Royal Central Institute for Meteorology and Geodynamics.)

\section{German Twin=Engined A.E.G.=G. IV. Machine.}

This machine first made its appearance during raids towards the end of 1917 . It is the smallest of the enemy bombers. Its maximum span is about $6 \mathrm{ft}$., and its total length about $32 \mathrm{ft}$. The total weight loaded is about $8,08 \mathrm{olb}$. The machine has a central fuselage and a 260 h.p. Mercédès or a 250 h.p. Maybach motor on each side, supported on the lower wings.

The portion of the lower wings between the motors and the fuselage has all its ribs made of steel tube. The remainder of the wing structure has wooden ribs with two or three compression ribs of metal tube. The spars are of $55 \mathrm{~mm}$. tube, three to the upper plane and four to the lower, the latter being divided into two by the fuselage. The parts of the wings between the motors have rigid trailing edges but the rest have flexible ones. Portions of the trailing edges are cut away in the centre to admit of good visibility, the cut-away of the lower being much greater than that of the upper.

The upper wings are swept back a little, while the lower have a dihedral of 2. $5^{\circ}$. Ailerons are placed on the upper wings only, and are constructed with a framework of steel tube; they have curved trailing edges, the minimum chord being about the middle. They are also balanced and project beyond the tips of the upper and lower wings. The inner parts of the lower wings are covered with metallic sheet. Two pairs of struts are fitted on each side of the motors ; they are of steel tube and streamlined. The gap between the wings is from 8 to $8.5 \mathrm{ft}$., while the maximum chord is about $8 \mathrm{ft}$. There are two 50 litre petrol tanks placed side by side in the thickness of the upper central wing.

The tail members are very thick, the maximum thickness being about six inches. Rudder and elevators are both balanced. The fixed tailplane is nearly semi-circular in shape.

The fuselage is rectangular in section with a rounded back, terminating in a knife-edge at the tail. The top is of ply-wood with metal covering. The remainder is covered with fabric. All the interior framework is composed of steel tubes welded together autogenously. There are three cockpits, the middle one being for the pilot and the other two containing machine-gun racks and the bomb releases. Narrow passages are provided for gaining access from one pit to the next.

The two motors, with six cylinders in line, are supported by six streamlined tubes arranged in $\mathrm{V}$ form and extending from the seatings of the motors to the outer tubes of the under-carriages. A system of triangulation prevents all lateral movement. This consists of three steel tubes, one passing from the fuselage to the motor, a second from the motor to the inner leg of the chassis, and the third joining the first two. No tube is connected to the upper wing, which is at much lighter structure.

The airscrews are tractors of about $10.3 \mathrm{ft}$. diameter. 
The two undercarriages are each formed of four steel tubes, the outer two being fixed at the base of the motor and the inner pair to a point $2.62 \mathrm{ft}$. from the fuselage. Elasticity is ensured by fitting two groups of 18 metal springs between each wheel and the corresponding legs of the chassis.

There are three machine-guns, two on circular tracks and the third beneath the fuselage. The machine carried about 1,74 olb. of bombs and fuel sufficient for some three to five hours. ("Aérophile," June, 1918.)

\section{New Type of Observation Balloon.}

The chief of the aerostatic section of the Italian army, Major Aroria, and Signor Prassove, Director of the Italian Army Aircraft Works, have produced a new type of observation balloon providing much more satisfactory results than the Parseval-Sigsfeld kite balloon or the trilobal Caquot balloon. The new type is essentially a spherical aerostat fitted with what are equivalent to stabilising fins and acting as a kite. It may be employed in winds of over 55 miles per hour, whereas the Parseval-Sigsfeld type could not be safely used in winds exceeding I 2 miles per hour. The new type required a smaller gas volume for equal load and ceiling in a ratio of $5: 6$ and owing to its smaller dimensions is easily transported and housed, while in flight it presents a smaller target to aircraft fire. A further advantage in the employment of mooring cables of small section follows from its smaller head resistance, while, should the mooring cable snap, the observation balloon may be operated as a free balloon. ("L'Aeronauta," March, 1918.)

\section{The Grain of Wood with Special Reference to the Direction of the Fibres.}

This article defines the various terms used in the Forest Products Laboratory, Madison, Wisconsin, as follow :-

" Edge grain," when lumber is sawed along the radius of the annual rings. This is known also as "comb," or "vertical grain."

"Flat grain," when lumber is cut parallel or tangential to the grain.

"Straight grain" means that fibres run parallel to the main axis of tree.

"Spiral grain" means that fibres run spirally round tree.

"Diagonal grain", is the slanting of the wood fibres in a $\log$ brought about by causes other than "spiral grain" in the tree.

The methods used for determining the presence and slope of spiral and diagonal grain

are given.

(a) on the tangential faces,

(b) on faces not truly radial or tangential,

Other irregularities in the direction of the fibres are also treated, together with the effect of knots. (A. Kochler, "Aerial Age," August I2, I9I8.)

\section{The German H.W. Biplane C.L. II.}

The most interesting feature of the Hannover biplane, apart from the biplane tail, is the unusually deep body (five feet). The reason for choosing such a deep body, which must be of bad aerodynamic shape, would appear to be to give the pilot, as well as the gunner, a good view forward and upward by bringing their heads in line with the upper plane. The gun is elevated on a turret some distance above the main top of the body for similar reasons. To extend the range of the gun the machine is built with one pair of interplane struts on each side of the body. No stop, however, is provided to the gun to prevent hitting the lift wires.

Constructionally the body is a light framework covered with three-ply. 
The usual instruments were fitted on the dash, and in addition a couple of inclinameters of unusual type, one for indicating lateral level, mounted on the dash, and another for longitudinal angularity mounted on the starboard side of the cockpit.

The wings had approximately equal spars, but the chord of the upper was considerably greater than that of the lower. The tips of the top wing were raked and the wing flaps balanced and warped. Wing tips of the Bleriot type were used on the lower wing. The motive power was furnished by an Aryus engine, partly covered in, each three cylinders of which have a common exhaust. The under-carriage was of the Vee type and followed along standard lines.

An interesting feature with the biplane tail is that although the two fixed planes are connected by struts there is no wire bracing.

The article also gives a description of the bombing mechanism and three views of the fuselage and tail. ("Aerial Age," August 12, 1918.)

\section{Co=operation of Aeroplanes with Artillery.}

Referring to methods of signalling from an aeroplane, special mention is here made of the use of wireless. In the problem of co-operation certain limitations are imposed by the necessity of preventing other batteries from opening fire on the target whilst accurate ranging is proceeding, in the most direct transmission of observations of the fire, in localising to the observer the position of the battery, and in devising a distinctive signal code.

Four general methods of co-operation are described: (a) A preliminary aeroplane reconnaissance, followed by an allocation by the Artillery Commander of targets and aeroplanes to the units under his command; $(b)$ an aeroplane observer works in an allotted area direct with known batteries, and ranges targets he selects; (c) alternately, he locates a target and signals its position to the Group or Divisional Artillery Commander concerned, who directs a battery to open fire under signal direction from the machine; $(d)$ a selected battery is detailed per map square for close ranging. The observer reports on the nature of any located target, and the battery opens fire without further orders.

Overlapping of areas chosen for such operations is to be avoided. Special signals should be arranged to meet cases of emergency or to point to exceptionally favourable targets.

In regard to location of targets, direction and range are taken from the map square reported by the observer, who corrects fire by usual methods. For signalling the position of a hostile battery, the decimal location of the most visible flank should be given, and, in addition, the position of the other flanks, by clock code.

A knowledge is essential of the time of flight of shell in use. When target registration is being carried out, special precautions should be observed in signalling " change to fresh target." Simultaneous correction for line and range is recommended. Reference is made to codes to be adopted, when the gun of a battery has been ranged and correction is to be made for the remaining gun. (D. I. Lamb, "Air Service Journal," July I8, 1918.)

\section{Proposed Spanish Aeroplane Routes.}

Mention is made of a proposed mail and passenger aeroplane service between Madrid, Barcelona, and the Balearic Islands by a newly-formed company, which has applied for official authorisation. Time allowed from Madrid to the islands, four hours.

Other routes are, it is said, suggested by the company between Madrid and the North of Spain. ("Air Service Journal," July 18 , I918.) 


\section{June Aerial Mail Operations.}

This article summarises statistics given by the Post Office Dept. covering mail service operations between Washington and New York for June. No flights took place on Sunday. Figures are tabulated giving the mileage, time, and load per day. Total mileage flown stated to have been 10,640 miles in 151 hours 22 mins., $\mathrm{I}_{3}, 080-7 / 8 \mathrm{lb}$. carried, classified as $990-\mathrm{I} / 8 \mathrm{lb}$. aeroplane, and $\mathrm{I} 2,090-3 / 4 \mathrm{lb}$. ordinary mail. Of twenty-five trips, nineteen were completed by aeroplane route, and 8 per cent. of the flights defaulted owing to weather.

It is added that the Post Office Dept. states that mail was carried on July io in $2 \frac{1}{2}$ hours from Washington to New York, including the stop at Philadelphia. Average speed for entire trip amounted to over 90 m.p.h., and that between Philadelphia and New York to I 08 m.p.h. It is claimed that increasing familiarity of the pilots with flight conditions has resulted in a considerable shortening of the arerage time.

Compass direction is compared with the chart every ten minutes during flight, and at each of the larger towns on the route. ("Air Service Journal," July I8, I918.)

\section{Conventional Propeller Calculations.}

The present article explains in a concise form the general method adopted by American designers in the design of a propeller and the calculations whereby the principal factors are determined. These are mainly of an empirical nature obtained by experience.

In greneral the diameter of the blades should be made as large as possible without calusing them to be so narrow in proportion that they would flutter excessively where wood construction is used. The maximum blade width for the best practice should be about $1 / 12$ diameter, thus giving an aspect ratio of 6 for each blacle. While plan form does not affect efficiency to any great extent, it is an important factor for strength. A diagram is given of one suitable from both these points of view. As a rough rule the angle of attack may be taken as $2^{\circ}$ for aeroplane speeds above $100 \mathrm{~m} . \mathrm{p} . \mathrm{h}$., and $3^{\circ}$ for speeds below this value.

The method of computing blade widths supposes the blade divided into elements, each of which is treated as a separate aerofoil, and from the known properties of the latter for a representative section, the power absorbed is easily estimated. In general an average value of $L / D$ may be assumed with sufficient precision to be 20 . The equivalent average diameter of the blade is taken on this calculation as 0.58 times the actual diameter.

It is stated that the success obtained by the use of wooden propellers is mainly due to the high tensile strength, light weight, and flexibility of that material. The Alexibility is particularly vital in reducing stresses, since when the thrust is applied and the blade bends, the centrifugal force brings into existence a moment tending to restore it to its original position. On account of the lack of this property, steel propellers are unsuitable, since they cannot accommodate themselves to different Hying attitudes.

For any single flying attitude and air density this difficulty can be overcome, howerer, by off setting the centres of gravity of different sections so that the bending moment due to air pressure is compensated for by that due to centrifugal force. The author has conducted a large number of tests on steel propellers, photographs of the fractures in which are given. He admits that the results so far are discouraging, failures usually occurring suddenly with disastrous consequences to the structure.

The author discusses at some length the question of an adjustable-pitch propeller, whose function would be to maintain the efficiency constant at different 
speeds of the machine. This is based on a theory that the $L / D$ of the aerofoil section is the controlling factor in the propeller efficiency, a theory not borne out in practice. An analysis by the author of such a propeller shows no gain in efficiency. There is, however, a net gain in h.p. delivered, owing to the increased engine speed in climbing; the gain in the rate of climb is about 49 per cent. He considers a propeller of this type of fairly light weight can be built for a smoothrunning engine, such as the Liberty twelve, but anticipates trouble with engines possessing an inherent vibration. (F. W. Caldwell, "Aviation," August I, I918.)

\section{Determination of Permeability of Balloon Fabrics.}

On account of the necessity for rendering balloon envelopes yas-tight, the determination of the permeability of fabrics to hydrogen is of prime importance in selecting suitable material for balloon construction. This paper discusses the results of investigations of methods used by the Bureau of Standards for determining these factors. Most balloon envelopes are made from rubber-coated silk or cotton, two plies of cloth being used with a gas-tight rubber film between them. The two plies are either placed parallel or at $45^{\circ}$ to each other, the latter being supposed to offer greater resistance to tearing. Anything from 100 to I 30 grams of rubber per sq. metre are present; the fabric is sometimes protected on the outside by a rubber coating.

Gas escapes from a balloon either through leaks at valves and imperfections in the fabric or by actual passage through the fabric. In the latter case the gas either diffuses through minute holes or it dissolves in the rubber film on the one side and evaporates on the other. Usually both processes occur simultaneously. If gases escape through these films by diffusion, the relative rates of escape should be approximately inversely proportional to the square roots of their densities, but this has been found not to be the case. The effect of change of temperature is also much greater than can be accounted for by the diffusion theory, and for these and other reasons it is known that the gases panetrate mainly by solution.

The permeability of a fabric is defined as the rate at which it is penetrated by a gas, usually hydrogen, and is expressed in litres of hydrogen per square metre per 24 hours, the volume being corrected to $0^{\circ} \mathrm{C}$. and $7^{600 \mathrm{~mm}}$. pressure.

Two methods are used for determining this quantity: ( $\mathrm{I}$ ) Depending on a measurement of the rate of decrease of a mass of hydrogen separated from the atmosphere by a definite area of fabric-the volume-loss method; (2) depending on a measurement of the volume of hydrogen passing through a definite area of fabric in a given period.

The volume-loss method clearly does not determine permeability directly, because what is measured is the volume of hydrogen escaping, minus volume of air entering, i.e., it measures difference in permeability to hydrogen and to air.

The usual apparatus for applying the volume-loss method is the RenardSurcout balance, consisting of the bell of a small gas-holder mounted on one arm of a balance, the top of the bell being closed by the fabric. The bell moves up and down in annular space filled with water, the annular container being attache 3 to the base of the balance. After filling the bell with hydrogen, the proper pressure is then obtained by adjusting the opposite balance arm with weights, and consequently, as the hydrogen escapes, the bell sinks and the pointer on a calibrated scale indicates the volume-loss.

The usual penetration method employs a cell divided by the fabric in two chambers in one of which is hydrogen at a definite pressure, while a stream of air in the other chamber carries away the hydrogen as it penetrates, the quantity of the latter being determined by burning and weighing. Sometimes a gas interferometer is used. A modified form of this is employed by Barr and Rosenhain at the National Physical Laboratory. 
The method adopted at the Bureau of Standards is in essence similar to the above, and numerous precautions are taken to preserve the purity of the gases used. The quantity of hydrogen carried away is, however, measured by means of the interferometer. In this instrument the difference in refractivity of two samples of gas contained in two chambers, $100 \mathrm{~cm}$. long, is measured; light is passed through both from a single slit, after which the two beams combine to produce interference fringes. The optical paths can be brought to equality by a tilting glass compensator. On a change in composition of the gas in one of the chambers a corresponding tilt of the plate to bring the fringes back to their original positions measures the difference in composition.

A number of curves are given, showing the effect of temperature on permexbility for different fabrics. They are all similar in shape, indicating that for fabrics of different compositions permeability increases with temperature practically according to the same law. Some discrepancies, however, on this point appear to be shown by different experimenters.

There is very little effect due to increased pressure. To determine the effect of humidity the permeability is measured when the gases are dry, and when moist, the experiments being repeated alternately on the same fabric. The fabric is about 6 per cent. more permeable when the gases are dry than when wet. (" Aviation," August I, I918.) 